\title{
Prognostic significance of platelet-to-lymphocyte ratio in urothelial carcinoma patients: a meta-analysis
}

\author{
Yuhai Bao ${ }^{*}$, Yin Wang, Xiaodong Li, Mingjun Pan, Hongze Zhang, Zegen Cheng and Xueyi Wang
}

\begin{abstract}
Background: The prognostic value of pre-treatment platelet-to-lymphocyte ratio (PLR) in patients with urothelial carcinoma (UC) remains controversial. Therefore, this meta-analysis aimed to identify the prognostic impact of PLR on UC.

Methods: The PubMed, Embase, Web of Science, and Cochrane Library databases were systematically searched. Hazard ratios (HRs) with 95\% confidence intervals (Cls) were used to summarize the correlations between PLR and overall survival (OS), progression-free survival (PFS), disease-free survival (DFS), and cancer-specific survival (CSS). Odds ratios (ORs) with 95\% Cls were used to measure the association between PLR and tumor clinicopathological factors.
\end{abstract}

Results: The meta-analysis included 15 studies published from 2015 to 2019 with a total of 5354 patients. Overall, a high PLR was correlated to poorer PFS ( $H R=1.81,95 \% \mathrm{Cl} 1.28-2.56, p=0.001)$ and DFS (HR=1.09, 95\% Cl 1.31-2.16, $\mathrm{p}<0.001)$ but not poor OS ( $H R=1.23,95 \% \mathrm{Cl} 0.95-1.59, \mathrm{p}=0.124)$ or CSS $(H R=1.000,95 \% \mathrm{Cl} 0.998-1.002, \mathrm{p}=0.919)$ in UC. In addition, an elevated PLR was correlated with patient age $>65$ years $(\mathrm{OR}=1.72,95 \% \mathrm{Cl} 1.25-2.38, \mathrm{p}=0.001)$ and hypertension $(\mathrm{OR}=1.48,95 \% \mathrm{Cl} 1.01-2.18, \mathrm{p}=0.046)$. However, no significant association was observed between $P L R$ and sex $(O R=0.79,95 \% \mathrm{Cl} 0.56-1.14, p=0.206)$ or diabetes $(O R=1.29,95 \% \mathrm{Cl} 0.77-2.15, p=0.333)$.

Conclusions: Our results demonstrated a significant correlation between elevated PLR and poor prognosis in UC. The prognostic role of PLR may help guide the management and prognostication of UC patients.

Keywords: Upper tract urothelial carcinoma, Platelet-to-lymphocyte ratio, Meta-analysis, Survival, Tumor stage

\section{Background}

Urothelial carcinomas (UCs) are the fourth most prevalent tumors [1]. Upper tract urothelial carcinomas (UTUC) are tumors derived from the urothelium along the urinary tract [2]. UTUCs are rare, accounting for only $5-10 \%$ of all UCs $[3,4]$, while bladder cancer (BC) accounts for $90 \%$ of all UCs. Sixty percent of UTUCs are diagnosed at the invasive stage, and peak incidence is observed in patients aged 70-90 years [5]. Regardless of the tumor location in the upper urinary tract, radical nephroureterectomy (RNU) with bladder cuff resection is considered the standard treatment for most UTUC

*Correspondence: 20223485@qq.com

Department of Urology, General Hospital of Benxi Iron \& Steel Industry Group of Liaoning Health Industry Group, Benxi 117000, Liaoning, China patients [5]. Although an adequate surgical treatment, the 5-year cancer-specific mortality remains high, ranging from $20 \%$ to $30 \%$ [6]. Seventy-five percent of BC patients are diagnosed with non-muscle-invasive bladder cancer (NMIBC), which has a high risk of recurrence. Various prognostic factors such as p53 protein, nuclear factor-kB, and osteopontin have been investigated in UC, but the prognostic efficiency remains unsatisfactory [2]. Therefore, it is important to identify reliable and effective prognostic biomarkers to aid UC prognostication and treatment.

Recent studies have shown that inflammation and immune responses play a role in cancer development [7-9]. The systemic inflammatory response (SIR) can substantially influence UC progression [10-12]. A series of hematological parameters, reflecting the immune 
status of cancer patients, have been widely explored as prognostic markers in recent years [13-15]. Neutrophilto-lymphocyte ratio (NLR), lymphocyte-to-monocyte ratio (LMR), and platelet-to-lymphocyte ratio (PLR) are non-invasive and cost-effective prognostic indicators for solid tumors [16-19]. Recent retrospective studies have reported inconsistent findings regarding the prognostic impact of PLR in UC [11, 12, 20-32]. For example, some studies reported a positive association between a high PLR and poor survival in UC [24, 29], whereas others did not [20] or even showed the opposite trend [12,30]. Therefore, the present meta-analysis aimed to estimate the prognostic role of PLR for different survival outcomes in UC. Furthermore, the associations between PLR and various clinicopathological factors were also analyzed.

\section{Materials and methods}

\section{Search strategy}

The PubMed, Embase, Web of Science, and Cochrane Library electronic databases were systematically searched to identify relevant studies. The following terms were used in the literature search: "platelet lymphocyte ratio", "PLR", "platelet to lymphocyte ratio", "urothelial carcinoma", "urothelial cancer", "bladder cancer", "bladder tumor", "upper urinary tract cancer", "upper tract urothelial carcinoma", and "UTUC". The last search was updated on September 16, 2019. The reference lists of relevant articles were also examined for additional potential inclusions. This meta-analysis was performed in accordance with the Preferred Reporting Items for Systematic Reviews and Meta-analyses (PRISMA) statement [33]. Ethical approval and informed consent were waived because all studies included in this meta-analysis were previously published.

\section{Inclusion criteria and exclusion criteria}

The inclusion criteria were (1) pathologically or histologically confirmed diagnosis of UC; (2) studies evaluating the correlation between PLR and overall survival (OS), progression-free survival (PFS), disease-free survival (DFS), and/or cancer-specific survival (CSS); (3) defined PLR cut-off value; (4) preoperative blood cell counts; (5) hazard ratio (HR) and 95\% confidence interval (CI) provided or able to be calculated from the available information; and (6) studies published as full-text in English. The exclusion criteria were (1) case reports, reviews, meeting abstracts, or letters; (2) studies with overlapping or duplicate data; and (3) studies without sufficient or usable data.

\section{Data extraction}

Two investigators (Y.B and Y.W) independently reviewed all candidate studies, and any disagreements were resolved by discussion with a third investigator (X.L). The following information was extracted from each eligible study: first author, year of publication, country, study period, number of patients, sex, age, treatment, cut-off value, ethnicity, survival analysis, and HRs of PLR for OS, PFS, DFS, and CSS with their 95\% CIs.

\section{Quality assessment}

Study quality was evaluated using the Newcastle-Ottawa scale (NOS) [34]. The NOS consists of three parts: selection, outcome, and comparability. The scores range from 0 to 9 , and studies with NOS scores $\geq 6$ are considered to be high-quality studies.

\section{Statistical analysis}

This meta-analysis was conducted using Stata 12.0 (Stata Corp, College Station, TX, USA). Heterogeneity among studies was estimated using Cochran's Q test [35] and Higgins' I-squared statistics [36]. A random-effects model was used for studies with significant heterogeneity $\left(I^{2}>50 \%\right.$ or $\left.\mathrm{Ph}<0.10\right)$. Otherwise, a fixed-effects model was used. A pooled $\mathrm{HR}>1$ with $95 \% \mathrm{CI}$ not overlapping $1(\mathrm{p}<0.05)$ indicated worse OS, PFS, DFS, and CSS for a high PLR in UC. Subgroup analyses were performed to investigate the factors influencing the prognostic function of PLR. The correlation between PLR and clinicopathological factors were measured by pooled odds ratios (ORs) and 95\% CIs. Publication bias was determined using Begg's funnel plots and Egger's linear regression tests. $\mathrm{p}$-values $<0.05$ were considered statistically significant.

\section{Results}

Selection and characteristics of the included studies

The process of literature selection is shown in Fig. 1. The initial literature search identified 142 studies and excluded 44 duplicate records. The remaining 98 studies were screened by title and/or abstract, and 58 studies were excluded. Subsequently, 40 full-text articles were evaluated, and 25 studies were removed for the following reasons: insufficient information $(n=13)$, not involving PLR $(\mathrm{n}=7)$, no survival data $(\mathrm{n}=4)$, and not involving UC $(\mathrm{n}=1)$. Finally, 15 studies [11, 12, 20-32] with a total of 5354 patients were included in the meta-analysis. The major characteristics of the 15 eligible studies are presented in Table 1 . These studies were published from 2015 to 2019 and were conducted in six countries including China $(\mathrm{n}=5)[21,22,25,27,32]$, Korea $(\mathrm{n}=4)[20$, 26, 29, 31], Japan $(n=3)[11,12,30]$, Austria $(n=1)$ [24], Poland $(n=1)$ [28], and Turkey $(n=1)$ [23]. The sample sizes ranged from 113 to 1551 , with a median value of 186. The cut-off PLR values varied from 111 to 241 . Eight studies [12, 20, 22-25, 29, 30] investigated the prognostic 

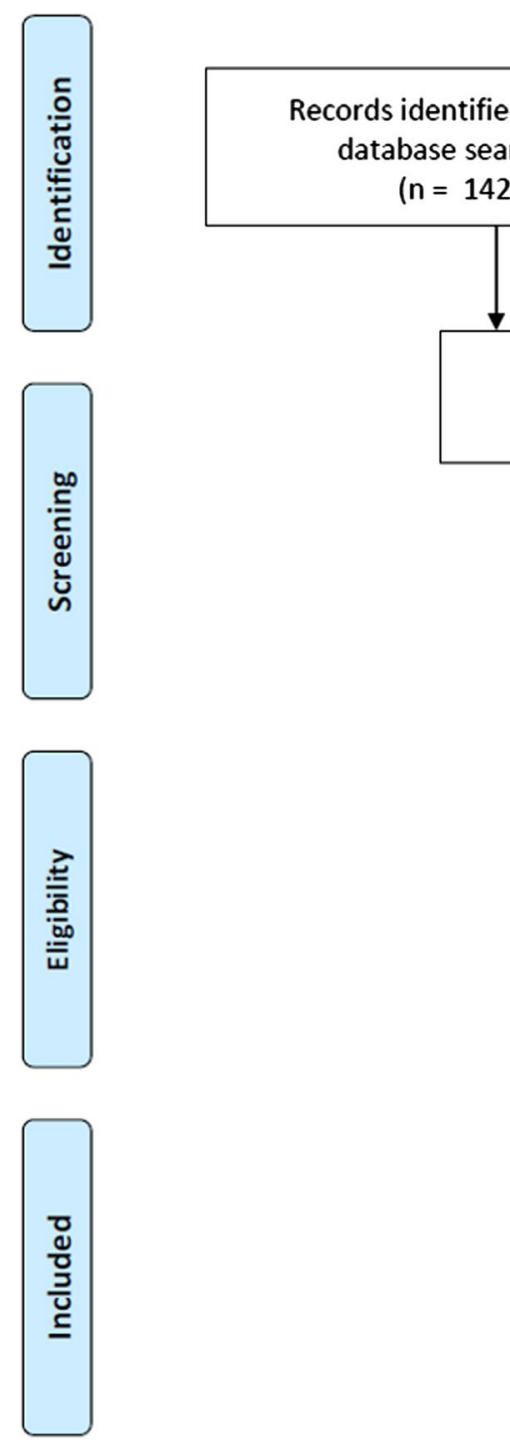

Records after duplicates removed
\[ (\mathrm{n}=98) \] through other sources $(n=0)$
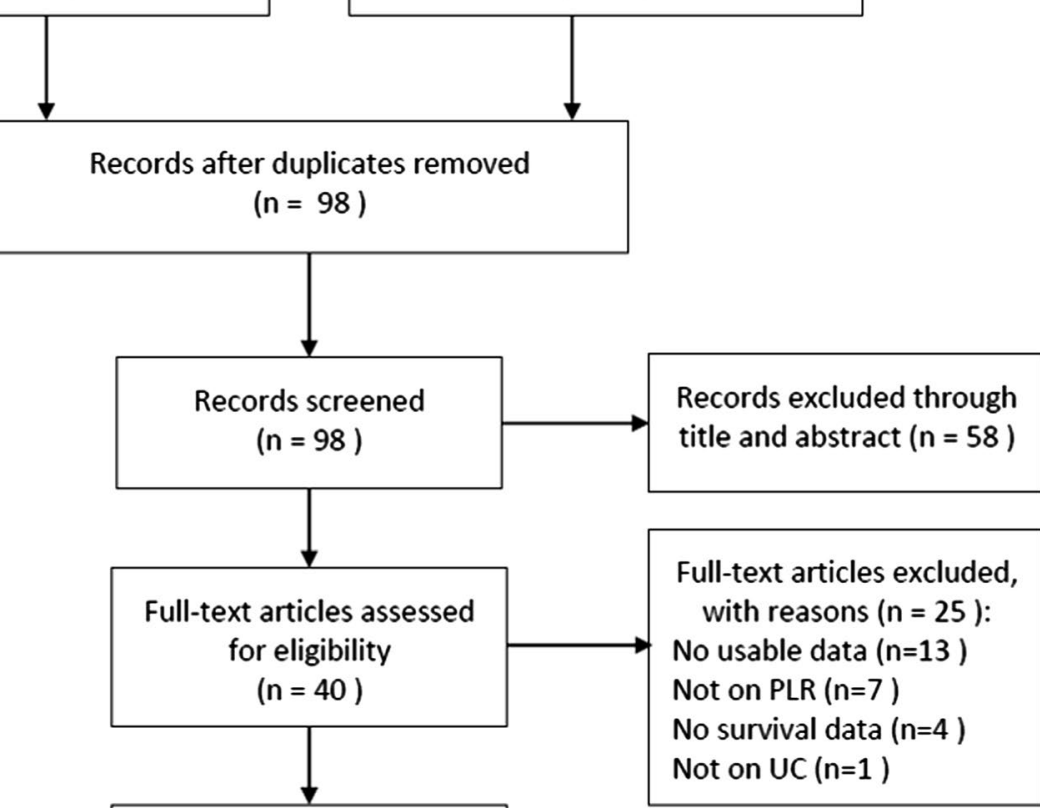

Studies included in

qualitative synthesis $(n=15)$

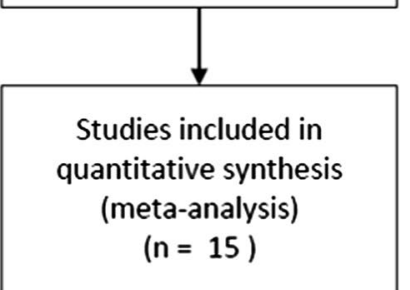

Fig. 1 The flow diagram indicated the process of study selection

value of PLR in UTUC while seven studies focused on BC $[11,21,26-28,31,32]$. Regarding the prognostic role of PLR in UC, nine studies reported OS $[11,12,21,24-26$, $28,31,32]$, seven studies reported PFS [22-25, 27, 29, $30]$, six studies reported DFS [20,22, 23, 27, 29, 30], and five studies provided data on CSS [11, 20, 26, 28, 31]. All studies had NOS scores $\geq 6$.

\section{Impact of PLR on OS, PFS, DFS, and CSS}

Nine studies [11, 12, 21, 24-26, 28, 31, 32] provided data on the relationship between PLR and OS. The pooled HR and $95 \%$ CI were: 1.23 and $0.95-1.59$, respectively $(\mathrm{p}=0.124)$ (Table 2, Fig. 2), indicating that PLR was not a significant marker for OS. Subgroup analysis showed that
PLR was associated with worse OS in patients receiving radical nephroureterectomy (RNU) (HR $=2.13$, 95\% CI 1.48-3.07, $\mathrm{p}<0.001$; Table 2), although this subgroup included only two studies. Seven studies [22-25, 27, 29, 30] reported the impact of PLR on PFS. The pooled HR and corresponding 95\% CI were 1.81 and $1.28-2.56$, respectively $(\mathrm{p}=0.001)$ (Table 2 , Fig. 2$)$. Subgroup analysis showed that PLR remained a significant indicator for PFS irrespective of sample size and tumor type. Six studies $[20,22,23,27,29,30]$ evaluated DFS. The pooled HR was 1.09 (95\% CI 1.31-2.16, p<0.001) (Table 2, Fig. 2). The subgroup analysis demonstrated that PLR remained correlated with poor DFS in patients with UTUC and $\mathrm{BC}$ as well as patients receiving RNU and transurethral 
Table 1 The basic information and data of all included studies in the meta-analysis

\begin{tabular}{|c|c|c|c|c|c|c|c|c|c|c|}
\hline Author & Year & Country & No. of patients & $\operatorname{Sex}(M / F)$ & Tumor type & $\begin{array}{l}\text { Age (years) } \\
\text { Median (range) }\end{array}$ & Cut-off value & Survival analysis & Treatment & NOS score \\
\hline Kim & 2015 & Korea & 277 & $218 / 59$ & UTUC & $63.7(29.5-90)$ & 150 & CSS, DFS & NUx & 7 \\
\hline Zhang & 2015 & China & 124 & $100 / 24$ & $B C$ & $65(30-78)$ & 140 & OS & $\mathrm{RC}$ & 8 \\
\hline Song & 2016 & China & 140 & $86 / 54$ & UTUC & $67(39-81)$ & 128 & DFS, PFS & RNU & 6 \\
\hline Altan & 2017 & Turkey & 113 & $86 / 27$ & UTUC & 63.7 & 150 & DFS, PFS & RNU & 7 \\
\hline Dalpiaz & 2017 & Austria & 180 & $109 / 71$ & UTUC & 70 & 150 & OS, PFS & RNU & 8 \\
\hline Huang & 2017 & China & 481 & $311 / 170$ & UTUC & $65(30-89)$ & 241 & OS, PFS & RNU & 7 \\
\hline Kang & 2017 & Korea & 1551 & $1302 / 249$ & $B C$ & $65(57-72)$ & 124 & OS, CSS & TURB & 7 \\
\hline Mao & 2017 & China & 207 & $169 / 38$ & $B C$ & $66(59-80)$ & 123 & DFS, PFS & TURB & 8 \\
\hline Miyake & 2017 & Japan & 117 & $95 / 22$ & $B C$ & 72 & 150 & OS, CSS & $\mathrm{RC}$ & 8 \\
\hline Rajwa & 2018 & Poland & 144 & NA & $B C$ & NA & 161 & OS, CSS & $\mathrm{RC}$ & 6 \\
\hline Son & 2018 & Korea & 1137 & $825 / 312$ & UTUC & 69 & 142 & DFS, PFS & RNU & 6 \\
\hline Itami & 2019 & Japan & 125 & $96 / 29$ & UTUC & 72 (38-90) & 150 & OS, DFS & $N U x$ & 7 \\
\hline Kuroda & 2019 & Japan & 187 & $138 / 49$ & UTUC & $71(38-90)$ & 165 & DFS, PFS & RNU & 7 \\
\hline Yuk & 2019 & Korea & 385 & $327 / 58$ & $B C$ & 72.6 & 171 & OS, CSS & TURB & 7 \\
\hline Zhu & 2019 & China & 186 & $157 / 29$ & $B C$ & 65 & 111 & OS & $\mathrm{RC}$ & 7 \\
\hline
\end{tabular}

OS overall survival, DFS disease-free survival, PFS progression-free survival, CSS cancer-specific survival, NUx nephroureterectomy, RC radical cystectomy, RNU radical nephroureterectomy, TURB transurethral resection of bladder tumor, NA not available, NOS Newcastle-Ottawa Scale, UTUC upper tract urothelial carcinoma, BC bladder cancer

resection of bladder tumor (TURB) (Table 2). Five studies provided CSS data $[11,20,26,28,31]$ with pooled HR and $95 \%$ CI of 1.000 and $0.998-1.002$, respectively $(p=0.919)$. The subgroup analysis indicated that PLR was not associated with CSS regardless of sample size, tumor type, or treatment method.

\section{Correlations between PLR and clinicopathological factors in UC}

Four studies [21, 22, 24, 27] provided relevant data on the associations between PLR and clinicopathological characteristics. The associations between PLR and clinical factors were calculated using pooled ORs. As shown in Fig. 3, the pooled ORs and 95\% CIs indicated that a high PLR was correlated to patient age $>65$ years $(\mathrm{OR}=1.72$, 95\% CI 1.25-2.38, $\mathrm{p}=0.001$; Fig. 3) and hypertension $(\mathrm{OR}=1.48,95 \%$ CI 1.01-2.18, $\mathrm{p}=0.046$; Fig. 3). However, no significant association was found between PLR and sex $(\mathrm{OR}=0.79,95 \% \mathrm{CI} 0.56-1.14, \mathrm{p}=0.206)$ or diabetes $(\mathrm{OR}=1.29,95 \%$ CI $0.77-2.15, \mathrm{p}=0.333)$ (Fig. 3).

\section{Publication bias}

Publication bias was examined by both Begg' s and Egger's tests. We found no significant publication bias in OS $(p=0.917$ for Begg's test; $p=0.209$ for Egger's test), PFS ( $p=0.230$ for Begg's test; $p=0.131$ for Egger's test), DFS ( $p=0.851$ for Begg's test; $p=0.599$ for Egger's test), or CSS ( $\mathrm{p}=0.462$ for Begg's test; $\mathrm{p}=0.368$ for Egger's test).

\section{Discussion}

The present study comprehensively searched relevant databases and collected data from 15 cohort studies containing 5354 patients. The pooled results suggested that an elevated PLR predicted an inferior PFS and unfavorable DFS in UC patients. The subgroup analysis showed that the prognostic value of PLR for DFS and PFS was not influenced by tumor type. Moreover, the pooled data also indicated that a high PLR was associated with patient age $>65$ years and hypertension. To our knowledge, ours is the first meta-analysis to investigate the prognostic ability of PLR in patients with UC. As PLR is non-invasive and easily accessible, it has the potential to guide clinical decision-making.

Recent studies using meta-analytic methods also focused on the association between PLR and prognosis for various types of cancer [17]. Lin et al. showed that a high pretreatment PLR predicted worse $\mathrm{OS}(\mathrm{HR}=1.73$, 95\% CI 1.46-2.04, $\mathrm{p}<0.001)$ and DFS $(\mathrm{HR}=1.30,95 \% \mathrm{CI}$ $1.06-1.60, \mathrm{p}=0.01$ ) in hepatocellular carcinoma patients with different Barcelona Clinic Liver Cancer (BCLC) stages [37]. Similarly, Wang et al. also reported an association between an elevated PLR and poor OS $(\mathrm{HR}=1.85$, 95\% CI $1.51-2.25, \mathrm{p}<0.001)$ as well as DFS $(\mathrm{HR}=1.4$, 95\% CI 1.1-1.79, $\mathrm{p}=0.007$ ) in prostate cancer patients [38]. Another work showed the prognostic value of PLR for worse OS $(H R=1.38,95 \%$ CI 1.19-1.62, $\mathrm{p}<0.001)$ and poor RFS or PFS (HR $=1.55,95 \%$ CI $1.27-1.88, \mathrm{p}<0.001)$ in patients with cholangiocarcinoma [39]. The findings of previous studies were in line with those of the current 
Table 2 Subgroup analysis of the relationship between PLR and OS, PFS, DFS, and CSS in UC

\begin{tabular}{|c|c|c|c|c|c|c|}
\hline \multirow[t]{2}{*}{ Factors } & \multirow{2}{*}{$\begin{array}{l}\text { No. of } \\
\text { studies }\end{array}$} & \multirow[t]{2}{*}{ Effect model } & \multirow[t]{2}{*}{$\mathrm{HR}(95 \% \mathrm{Cl})$} & \multirow[t]{2}{*}{ p } & \multicolumn{2}{|c|}{ Heterogeneity } \\
\hline & & & & & $I^{2}(\%)$ & $\mathrm{Ph}$ \\
\hline \multicolumn{7}{|l|}{ OS } \\
\hline All & 9 & Random & $1.23(0.95-1.59)$ & 0.124 & 70.7 & 0.001 \\
\hline \multicolumn{7}{|c|}{ Sample size } \\
\hline$\leq 200$ & 6 & Random & $1.37(0.87-2.15)$ & 0.174 & 78.7 & $<0.001$ \\
\hline$>200$ & 3 & & & & & \\
\hline \multicolumn{7}{|c|}{ Tumor type } \\
\hline UTUC & 3 & Random & $1.47(0.70-3.12)$ & 0.309 & 80.2 & 0.006 \\
\hline$B C$ & 6 & Fixed & $1.002(1.000-1.004)$ & 0.049 & 36.1 & 0.166 \\
\hline \multicolumn{7}{|c|}{ Treatment } \\
\hline $\mathrm{RC}$ & 4 & Random & $1.27(0.83-1.95)$ & 0.266 & 56.8 & 0.074 \\
\hline $\mathrm{RNU}$ & 2 & Fixed & $2.13(1.48-3.07)$ & $<0.001$ & 47.6 & 0.167 \\
\hline TURB & 2 & Fixed & $0.95(0.74-1.22)$ & 0.666 & 0 & 0.409 \\
\hline NUx & 1 & - & $0.66(0.32-1.35)$ & 0.253 & - & - \\
\hline \multicolumn{7}{|l|}{ PFS } \\
\hline All & 7 & Random & $1.81(1.28-2.56)$ & 0.001 & 60.1 & 0.020 \\
\hline \multicolumn{7}{|c|}{ Sample size } \\
\hline$\leq 200$ & 4 & Random & $1.92(1.14-3.26)$ & 0.015 & 58 & 0.067 \\
\hline$>200$ & 3 & Random & $1.68(1.03-2.75)$ & 0.040 & 60.1 & 0.020 \\
\hline \multicolumn{7}{|c|}{ Tumor type } \\
\hline UTUC & 6 & Random & $1.67(1.2-2.31)$ & 0.002 & 54.8 & 0.050 \\
\hline$B C$ & 1 & - & $4.09(1.52-11.03)$ & 0.005 & - & - \\
\hline \multicolumn{7}{|l|}{ DFS } \\
\hline All & 6 & Fixed & $1.69(1.31-2.16)$ & $<0.001$ & 0.6 & 0.412 \\
\hline \multicolumn{7}{|c|}{ Sample size } \\
\hline$\leq 200$ & 3 & Fixed & $1.35(0.94-1.95)$ & 0.103 & 0 & 0.573 \\
\hline$>200$ & 3 & Fixed & $2.05(1.45-2.90)$ & $<0.001$ & 0 & 0.535 \\
\hline \multicolumn{7}{|c|}{ Tumor type } \\
\hline UTUC & 5 & Fixed & $1.54(1.17-2.02)$ & 0.002 & 0 & 0.672 \\
\hline$B C$ & 1 & - & $2.74(1.46-5.14)$ & 0.002 & - & - \\
\hline \multicolumn{7}{|c|}{ Treatment } \\
\hline RNU & 4 & Fixed & $1.54(1.17-2.04)$ & 0.002 & 0 & 0.504 \\
\hline TURB & 1 & - & $2.74(1.46-5.14)$ & 0.002 & - & - \\
\hline NUx & 1 & - & $1.50(0.47-4.80)$ & 0.499 & - & - \\
\hline \multicolumn{7}{|l|}{ CSS } \\
\hline All & 5 & Fixed & $1.000(0.998-1.002)$ & 0.919 & 0 & 0.859 \\
\hline \multicolumn{7}{|c|}{ Sample size } \\
\hline$\leq 200$ & 2 & Fixed & $1.000(0.998-1.002)$ & 0.923 & 0 & 0.635 \\
\hline$>200$ & 3 & Fixed & $1.23(0.82-1.85)$ & 0.311 & 0 & 0.968 \\
\hline \multicolumn{7}{|c|}{ Tumor type } \\
\hline UTUC & 1 & - & $1.20(0.37-3.86)$ & 0.757 & - & - \\
\hline$B C$ & 4 & Fixed & $1.000(0.998-1.002)$ & 0.919 & 0 & 0.748 \\
\hline \multicolumn{7}{|c|}{ Treatment } \\
\hline $\mathrm{RC}$ & 2 & Fixed & $1.000(0.998-1.002)$ & 0.923 & 0 & 0.635 \\
\hline TURB & 2 & Fixed & $1.24(0.80-1.91)$ & 0.334 & 0 & 0.801 \\
\hline NUx & 1 & - & $1.20(0.37-3.86)$ & 0.757 & - & - \\
\hline
\end{tabular}




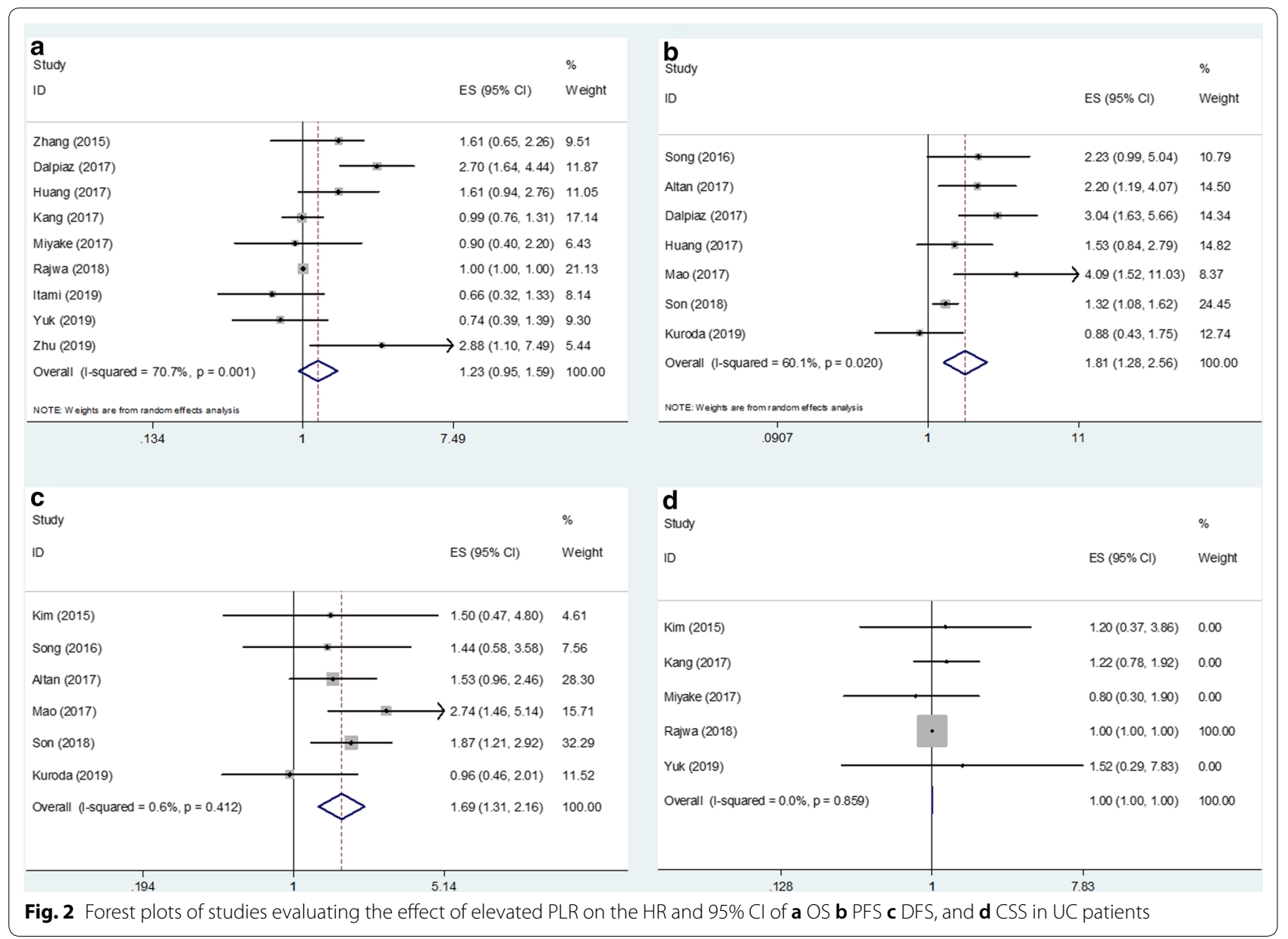

study. The present study computed the prognostic value and clinical significance of PLR using pooled HRs and ORs. For this reason, the results might not be applicable to individual patients because platelet and lymphocyte counts are influenced by multiple factors such as infection, inflammation, drug use, age, and baseline physical condition. Therefore, when applying PLR for prognostication of individual patients with UC, other clinicopathological factors should also be considered. Furthermore, cell counts performed at different sites could vary, which makes it difficult to normalize PLR.

The exact mechanisms by which PLR has prognostic value in UC patients remain unclear. Cancer cells can induce platelet activation by secreting platelet agonists [40]. Platelets also facilitate the proliferation of ovarian cancer cells in a transforming growth factor- $\beta 1$ (TGF- $\beta 1$ )-dependent manner [41]. Moreover, platelets can directly contact tumor cells and secret a series of cytokines including platelet-derived growth factor (PDGF), TGF- $\beta$, and prostaglandin (PG) E2, which can enhance the epithelial-mesenchymal transition (EMT) of tumor cells [42, 43]. In contrast, lymphocytes play important roles in anti-tumor immune responses. Intraepithelial $\mathrm{CD} 3+$ and $\mathrm{CD} 8+$ tumor-infiltrating $\mathrm{T}$ lymphocytes (TILs) were strongly associated with improved PFS and DFS in ovarian cancer patients [44]. Lymphocytes and interferon (IFN) gamma can collaborate to select to tumor cells to reduce immune surveillance [45]. CD8 + TILs have been associated with good prognosis in various cancers [46]. Therefore, evaluation of PLR is useful and convenient to predict clinical outcomes in patients with UC.

The present study had several limitations. First, the included studies were all retrospective, which may have caused a selection bias in the meta-analysis. Second, only four studies provided data on the association between PLR and clinical features. The sample size was too small. Third, we extracted pooled HRs and $95 \mathrm{CIs}$ from eligible studies but not individual patient information. Fourth, it is hard to normalize PLR because blood counts may vary at different sites, which may cause variability in the index values. Therefore, additional large-scale prospective studies are warranted to confirm our findings. 


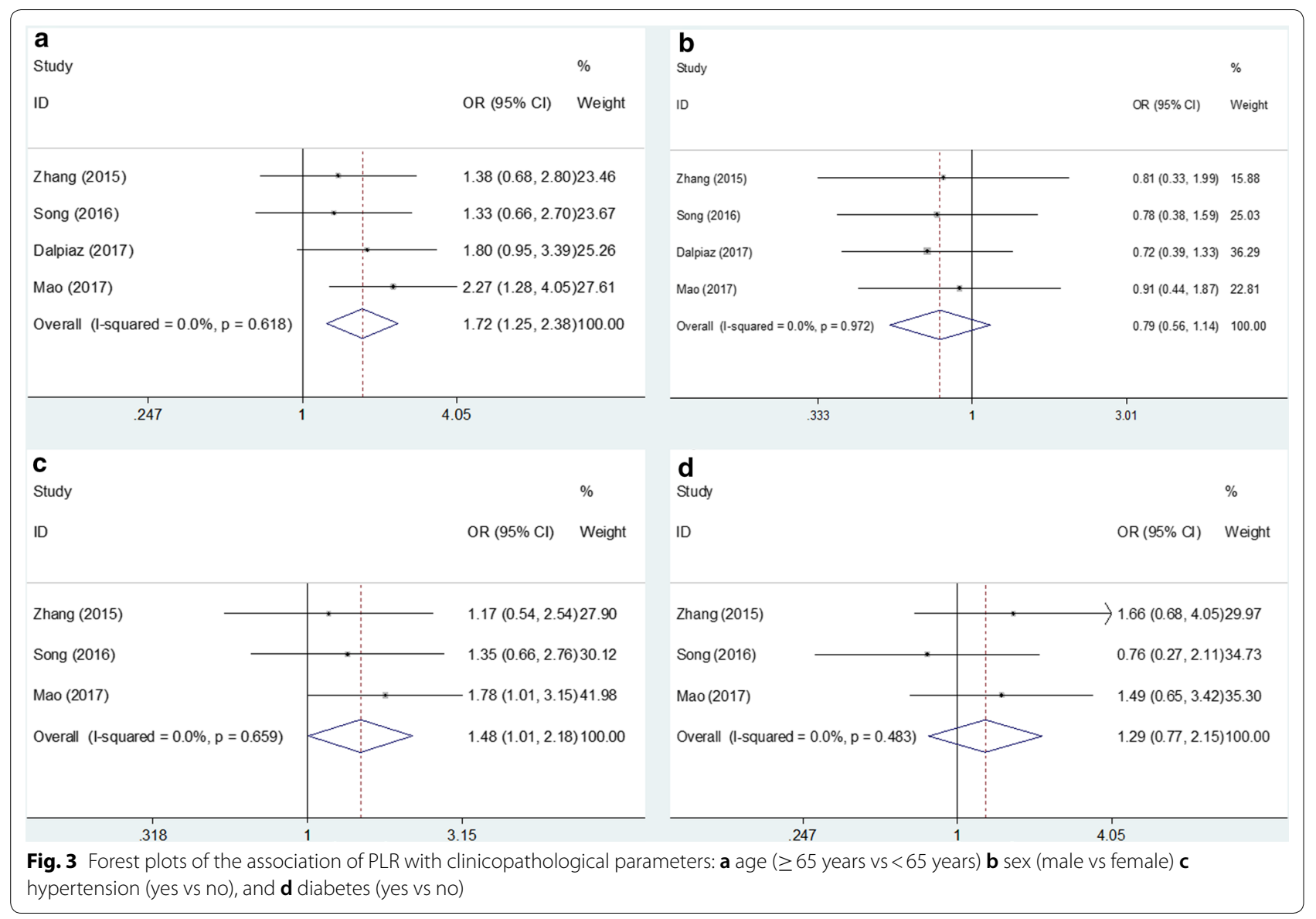

\section{Conclusions}

The results of this meta-analysis showed that PLR predicted worse DFS and PFS in UC. PLR was also correlated with older age and hypertension in patients with UC. The prognostic role of PLR may help to guide the administration of treatment and prognostication of UC patients.

\section{Abbreviations \\ PLR: platelet-to-lymphocyte ratio; UC: urothelial carcinoma; UTUC: upper tract urothelial carcinoma; BC: bladder cancer; HR: hazard ratio; Cl: confidence interval; OS: overall survival; DFS: disease-free survival; PFS: progression-free survival; UC: urothelial carcinoma; RNU: radical nephroureterectomy; SIR: systemic inflammatory response; NLR: neutrophil-to-lymphocyte ratio; LMR: lymphocyte-to-monocyte ratio; PRISMA: Preferred Reporting Items for System- atic Reviews and Meta-analyses; NOS: Newcastle-Ottawa scale.}

\section{Authors' contributions}

$\mathrm{YB}$ conceived, designed, supervised experiments. YW, XL, MP, HZ, and ZC collected and analyzed the data. YB and XW wrote the manuscript. All authors read and approved the final manuscript.

\section{Funding}

The authors declare that there are no sources of funding to be acknowledged.

\section{Availability of data and materials}

The data that support the findings of this study are available from the corresponding author upon reasonable request.

\section{Ethics approval and consent to participate}

Not applicable.

\section{Consent for publication}

Not applicable.

\section{Competing interests}

The authors declare that they have no competing interests.

Received: 5 Auqust 2019 Accepted: 12 November 2019

Published online: 27 November 2019

\section{References}

1. Roupret M, Babjuk M, Comperat E, Zigeuner R, Sylvester RJ, Burger M, Cowan NC, Gontero P, Van Rhijn BWG, Mostafid AH, et al. European association of urology guidelines on upper urinary tract urothelial carcinoma: 2017 update. Eur Urol. 2018;73(1):111-22.

2. Chien TM, Li CC, Li WM, Yeh HC, Ke HL, Lee HY, Chou YH, Huang SP, Huang $\mathrm{CN}$, Wu WJ. The significant prognosticators of upper tract urothelial carcinoma. Urol Sci. 2015;26(4):230-4. 
3. Green DA, Rink M, Xylinas E, Matin SF, Stenzl A, Roupret M, Karakiewicz PI, Scherr DS, Shariat SF. Urothelial carcinoma of the bladder and the upper tract: disparate twins. J Urol. 2013;189(4):1214-21.

4. Munoz JJ, Ellison LM. Upper tract urothelial neoplasms: incidence and survival during the last 2 decades. J Urol. 2000;164(5):1523-5.

5. Margulis V, Shariat SF, Matin SF, Kamat AM, Zigeuner R, Kikuchi E, Lotan Y, Weizer A, Raman JD, Wood CG, et al. Outcomes of radical nephroureterectomy: a series from the upper tract urothelial carcinoma collaboration. Cancer. 2009;115(6):1224-33.

6. Ploussard G, Xylinas E, Lotan Y, Novara G, Margulis V, Roupret M, Matsumoto K, Karakiewicz PI, Montorsi F, Remzi M, et al. Conditional survival after radical nephroureterectomy for upper tract carcinoma. Eur Urol. 2015:67(4):803-12.

7. Coussens LM, Werb Z. Inflammation and cancer. Nature. 2002;420(6917):860-7.

8. Mantovani A, Allavena P, Sica A, Balkwill F. Cancer-related inflammation. Nature. 2008;454(7203):436-44.

9. Grivennikov SI, Greten FR, Karin M. Immunity, inflammation, and cancer. Cell. 2010;140(6):883-99.

10. Vartolomei MD, Kimura S, Ferro M, Vartolomei L, Foerster B, Abufaraj M, Shariat SF. Is neutrophil-to-lymphocytes ratio a clinical relevant preoperative biomarker in upper tract urothelial carcinoma? a meta-analysis of 4385 patients. World J Urol. 2018;36(7):1019-29.

11. Miyake M, Morizawa Y, Hori S, Marugami N, lida K, Ohnishi K, Gotoh D, Tatsumi Y, Nakai Y, Inoue T, et al. Integrative assessment of pretreatment inflammation-, nutrition-, and muscle-based prognostic markers in patients with muscle-invasive bladder cancer undergoing radical cystectomy. Oncology. 2017;93(4):259-69.

12. Itami Y, Miyake M, Tatsumi Y, Gotoh D, Hori S, Morizawa Y, lida K, Ohnishi K, Nakai $Y$, Inoue T, et al. Preoperative predictive factors focused on inflammation-, nutrition-, and muscle-status in patients with upper urinary tract urothelial carcinoma undergoing nephroureterectomy. Int J Clin Oncol. 2019;24(5):533-45.

13. Zhang Y, Zheng L, Quan L, Du L. Prognostic role of platelet-to-lymphocyte ratio in oral cancer: a meta-analysis. J Oral Pathol Med. 2019. https:// doi.org/10.1111/jop.12832.

14. Xu WY, Wang WQ, Yang M, Song LN, Xiong JP, Lin JZ, Long JY, Bai Y, Zheng $Y C$, Zhao $L$, et al. Prognostic significance of the platelet-to-lymphocyte ratio in ovarian cancer: a meta-analysis. Transl Cancer Res. 2018;7(3):552.

15. Nishijima TF, Muss HB, Shachar SS, Tamura K, Takamatsu Y. Prognostic value of lymphocyte-to-monocyte ratio in patients with solid tumors: a systematic review and meta-analysis. Cancer Treat Rev. 2015;41(10):971-8.

16. Li JL, Cheng YS, Ji ZG. Prognostic value of pretreatment lymphocyte-tomonocyte ratio in patients with urologic tumors a PRISMA-compliant meta-analysis. Medicine. 2019;98(2):e14091.

17. Zhou X, Du YP, Huang ZB, Xu J, Qiu TZ, Wang J, Wang TS, Zhu W, Liu P. Prognostic value of PLR in various cancers: a meta-analysis. PLOS ONE. 2014;9(6):e101119.

18. Templeton AJ, Ace O, McNamara MG, Al-Mubarak M, Vera-Badillo FE, Hermanns T, Seruga B, Ocana A, Tannock IF, Amir E. Prognostic role of platelet to lymphocyte ratio in solid tumors: a systematic review and meta-analysis. Cancer Epidemiol Biomark Prev. 2014;23(7):1204-12.

19. Huang QT, Zhou L, Zeng WJ, Ma QQ, Wang W, Zhong M, Yu YH. Prognostic significance of neutrophil-tolymphocyte ratio in ovarian cancer: a systematic review and meta-analysis of observational studies. Cell Physiol Biochem. 2017:41(6):2411-8

20. Kim M, Moon KC, Choi WS, Jeong CW, Kwak C, Kim HH, Ku JH. Prognostic value of systemic inflammatory responses in patients with upper urinary tract urothelial carcinoma. World J Urol. 2015;33(10):1439-57.

21. Zhang GM, Zhu Y, Luo L, Wan FN, Zhu YP, Sun LJ, Ye DW. Preoperative lymphocyte-monocyte and platelet-lymphocyte ratios as predictors of overall survival in patients with bladder cancer undergoing radical cystectomy. Tumor Biol. 2015;36(11):8537-43.

22. Song X, Zhang GM, Ma XC, Luo L, Li B, Chai DY, Sun L. Comparison of preoperative neutrophil-lymphocyte, lymphocyte-monocyte, and platelet-lymphocyte ratios in patients with upper urinary tract urothelial carcinoma undergoing radical nephroureterectomy. Oncotargets Ther. 2016:9:1399-407.

23. Altan M, Haberal HB, Akdogan B, Ozen H. A critical prognostic analysis of neutrophil-lymphocyte ratio for patients undergoing nephroureterectomy due to upper urinary tract urothelial carcinoma. Int J Clin Oncol. 2017;22(5):964-71.

24. Dalpiaz O, Krieger D, Ehrlich GC, Pohlmann K, Stojakovic T, Pummer K, Zigeuner R, Pichler M, Hutterer GC. Validation of the preoperative platelet-to-lymphocyte ratio as a prognostic factor in a European cohort of patients with upper tract urothelial carcinoma. Urol Int. 2017;98(3):320-7.

25. Huang J, Yuan Y, Wang Y, Zhang J, Kong W, Chen H, Chen Y, Huang Y. Prognostic value of preoperative plasma fibrinogen level and platelet-tolymphocyte ratio (F-PLR) in patients with localized upper tract urothelial carcinoma. Oncotarget. 2017;8(22):36761-71.

26. Kang M, Jeong CW, Kwak C, Kim HH, Ku JH. Preoperative neutrophillymphocyte ratio can significantly predict mortality outcomes in patients with non-muscle invasive bladder cancer undergoing transurethral resection of bladder tumor. Oncotarget. 2017:8(8):12891-901.

27. Mao SY, Huang TB, Xiong DD, Liu MN, Cai KK, Yao XD. Prognostic value of preoperative systemic inflammatory responses in patients with nonmuscle invasive bladder cancer undergoing transurethral resection of bladder tumor. Int J Clin Exp Pathol. 2017;10(5):5799-810.

28. Rajwa P, Zyczkowski M, Paradysz A, Bujak K, Bryniarski P. Evaluation of the prognostic value of LMR, PLR, NLR, and dNLR in urothelial bladder cancer patients treated with radical cystectomy. Eur Rev Med Pharmacol Sci. 2018;22(10):3027-37.

29. Son S, Hwang EC, Jung SI, Kwon DD, Choi SH, Kwon TG, Noh JH, Kim MK, Seo IY, Kim CS, et al. Prognostic value of preoperative systemic inflammation markers in localized upper tract urothelial cell carcinoma: a large, multicenter cohort analysis. Minerva Urol Nefrol. 2018;70(3):300-9.

30. Kuroda K, Asakuma J, Horiguchi A, Kawaguchi M, Shinchi M, Masunaga A, Tasaki S, Sato A, Ito K. Chronic kidney disease and positive surgical margins as prognosticators for upper urinary tract urothelial carcinoma patients undergoing radical nephroureterectomy. Mol Clin Oncol. 2019:10(5):547-54.

31. Yuk HD, Jeong CW, Kwak C, Kim HH, Ku JH. Elevated neutrophil to lymphocyte ratio predicts poor prognosis in non-muscle invasive bladder cancer patients: initial intravesical Bacillus Calmette-Guerin treatment after transurethral resection of bladder tumor setting. Front Oncolo. 2019. https://doi.org/10.3389/fonc.2018.00642.

32. Zhu ZW, Wang XJ, Wang JG, Wang SZ, Fan YF, Fu TL, Cao SQ, Zhang $X P$. Preoperative predictors of early death risk in bladder cancer patients treated with robot-assisted radical cystectomy. Cancer Med. 2019:8(7):3447-52.

33. Moher D, Liberati A, Tetzlaff J, Altman DG, Grp P. Preferred reporting items for systematic reviews and meta-analyses: the PRISMA statement. Br Med J. 2009. https://doi.org/10.1136/bmj.b2535.

34. Stang A. Critical evaluation of the Newcastle-Ottawa scale for the assessment of the quality of nonrandomized studies in meta-analyses. Eur J Epidemiol. 2010;25(9):603-5.

35. Cochran $\mathbf{W}$. The combination of estimates from different experiments. Biometrics. 1954;10:101-29.

36. Higgins JPT, Thompson SG. Quantifying heterogeneity in a meta-analysis. Stat Med. 2002;21(11):1539-58.

37. Lin WF, Zhong MF, Zhang YR, Wang H, Zhao HT, Cheng BB, Ling CQ. Prognostic role of platelet-to-lymphocyte ratio in hepatocellular carcinoma with different BCLC stages: a systematic review and meta-analysis. Gastroenterol Res Pract. 2018. https://doi.org/10.1155/2018/5670949.

38. Wang JF, Zhou XF, He YH, Chen X, Liu NB, Ding ZS, Li JJ. Prognostic role of platelet to lymphocyte ratio in prostate cancer a meta-analysis. Medicine. 2018;97(40):e12504

39. Hu G, Liu Q, Ma JY, Liu CY. Prognostic significance of platelet-to-lymphocyte ratio in cholangiocarcinoma: a meta-analysis. Biomed Res Int. 2018 https://doi.org/10.1155/2018/7375169.

40. Plantureux L, Crescence L, Dignat-George F, Panicot-Dubois L, Dubois C. Effects of platelets on cancer progression. Thromb Res. 2018;164:S40-7.

41. Cho MS, Bottsford-Miller J, Vasquez HG, Stone R, Zand B, Kroll MH, Sood AK, Afshar-Kharghan V. Platelets increase the proliferation of ovarian cancer cells. Blood. 2012;120(24):4869-72.

42. Contursi A, Sacco A, Grande R, Dovizio M, Patrignani P. Platelets as crucial partners for tumor metastasis: from mechanistic aspects to pharmacological targeting. Cell Mol Life Sci. 2017;74(19):3491-507.

43. Labelle M, Begum S, Hynes RO. Direct signaling between platelets and cancer cells induces an epithelial-mesenchymal-like transition and promotes metastasis. Cancer Cell. 2011;20(5):576-90. 
44. Li J, Wang JY, Chen RF, Bai Y, Lu X. The prognostic value of tumor-infiltrating T lymphocytes in ovarian cancer. Oncotarget. 2017;8(9):15621-31.

45. Shankaran V, Ikeda H, Bruce AT, White JM, Swanson PE, Old LJ, Schreiber RD. IFN gamma and lymphocytes prevent primary tumour development and shape tumour immunogenicity. Nature. 2001;410(6832):1107-11.

46. Fridman WH, Pages F, Sautes-Fridman C, Galon J. The immune contexture in human tumours: impact on clinical outcome. Nat Rev Cancer. 2012;12(4):298-306.

\section{Publisher's Note}

Springer Nature remains neutral with regard to jurisdictional claims in published maps and institutional affiliations.
Ready to submit your research? Choose BMC and benefit from:

- fast, convenient online submission

- thorough peer review by experienced researchers in your field

- rapid publication on acceptance

- support for research data, including large and complex data types

- gold Open Access which fosters wider collaboration and increased citations

- maximum visibility for your research: over $100 \mathrm{M}$ website views per year

At BMC, research is always in progress.

Learn more biomedcentral.com/submissions 